\title{
Efektivitas Metode Hypnoteaching Dalam Pembelajaran Tematik Kelas V MIM 2 Babakan
}

\author{
${ }^{1}$ Puji Haryono, ${ }^{2}$ Abdul Wachid \\ ${ }^{1}$ Prodi Pendidikan Guru Madrasah Ibtidaiyah Pascasarjana, IAIN Purwokerto \\ ${ }^{2}$ Dosen/ Pendidikan Guru Madrasah Ibtidaiyah Pascasarjana, IAIN Purwokerto \\ Email: ${ }^{1}$ pujiharyono2@gmail.com, ${ }^{2}$ abdulwachidbs@iainpurwokerto.ac.id
}

\begin{abstract}
Abstrak. Penelitian ini merupakan penelitian kualitatif lapangan (field research) dan penelitian pustaka (library research). Adapun subyek penelitiannya adalah guru dan siswa di MIM 2 Babakan. Dengan teknik pengumpulan datanya adalah dengan menggunakan triangulasi data (data gabungan) yaitu menggunakan teknik observasi, wawancara, dan dokumentasi. Penelitian ini bertujuan untuk mengetahui efektivitas penggunaan metode hypnoteaching pada pembelajaran tematik kelas V di MIM 2 Babakan. Metode pada penelitian ini mengarah pada metode kualitatif adalah metode penelitian yang digunakan untuk meneliti pada kondisi objek yang alamiah. Hasil pada penelitian ini adalah dapat membuktikan bahwa penerapan metode hypnoteaching pada Pembelajaran Tematik Kelas V di Madrasah Ibtidaiyah Muhammadiyah 2 Babakan Kabupaten Purbalingga sudah berhasil dilakukan guna meningkatkan mutu pembelajaran. Penggunaan hypnoteaching membuat guru lebih mudah dalam mengelola pembelajaran dengan pola komunikasi yang baik. Dalam pelaksanaannya, langkah-langkah yang digunakan dalam hypnoteaching diantaranya adalah adanya motivasi diri, pacing, leading, modelling, dan memberikan pujian.
\end{abstract}

Kata Kunci: Metode Hypnoteaching, Pembelajaran Tematik, MIM 2 Babakan

\begin{abstract}
Abstrac. This research is a qualitative field research (field research) and library research or library research. The research subjects were teachers and students at MIM 2 Babakan. The data collection technique is by using data triangulation (combined data), namely using observation, interview, and documentation techniques. This study aims to determine the effectiveness of using the hypnoteaching method in class V thematic learning at MIM 2 Babakan. The method in this study leads to qualitative methods, which are research methods used to examine the conditions of natural objects. The results of this study are able to prove that the application of the hypnoteaching method in Class $V$ Thematic Learning at Madrasah Ibtidaiyah Muhammadiyah 2 Babakan, Purbalingga Regency has been successfully carried out in order to improve the quality of learning. The use of hypnoteaching makes it easier for teachers to manage learning with good communication patterns. In practice, the steps used in hypnoteaching include self-motivation, pacing, leading, modeling, and giving praise.
\end{abstract}

Keywords: Hypnoteaching Method, Thematic Learning, MIM 2 Babakan

Jurnal Ilmu Sosial dan Pendidikan 


\section{PENDAHULUAN}

Proses pembelajaran merupakan kegiatan inti dari proses pendidikan secara keseluruhan. Proses pembelajaran merupakan proses yang mengandung serangkaian kegiatan guru dan peserta didik atas dasar hubungan timbal balik yang berlangsung dalam suasana edukatif untuk mencapai tujuan pembelajaran. Interaksi atau hubungan timbal balik antara guru dan peserta didik merupakan syarat bagi berlangsungnya proses belajar mengajar. Guru sebagai pendidik harus mampu menciptakan interaksi yang baik dengan peserta didik, hal ini dikarenakan peranan guru sangat dibutuhkan dalam perubahan tingkah laku yang mencakup tiga aspek yaitu aspek kognitif, aspek afektif, dan aspek psikomotorik peserta didik. Dalam dunia pendidikan guru merupakan salah satu sumber belajar dari peserta didik. Guru dikatakan sebagai sesuatu yang dapat digugu dan ditiru, dalam artian bahwa guru merupakan sumber atau acuan dari peserta didik baik dalam bertingkah laku, bertutur kata, maupun dalam hal segi berpakaian. Suatu lembaga pendidikan harus memberikan sistem pembelajaran yang sesuai dengan kebutuhan siswa. Berhasil dan efektif tidaknya suatu pembelajaran pada dasarnya adalah tergantung pada sistem pembelajaran.

Guru memiliki peran dalam menentukan tercapainya tujuan pembelajaran. Tercapainya tujuan pembelajaran tersebut ditentukan oleh cara dan metode yang digunakan oleh guru. Metode tersebut yang akan mempengaruhi kondisi belajar siswa satu dengan siswa lainnya. Untuk Saat ini sudah banyak metode yang telah dikembangkan dan diterapkan di sekolah. Penggunaan bermacam-macam metode tersebut bertujuan agar kegiatan pembelajaran berlangsung menyenangkan, menarik, dan tentu saja efektif dalam mencapai tujuan pembelajaran.

Hakikatnya metode merupakan cara yang digunakan dalam melaksanakan suatu pekerjaan agar tercapai tujuan sesuai dengan yang dikehendaki, cara kerja yang bersistem untuk memudahkan pelaksanaan suatu kegiatan guna mencapai tujuan yang ditentukan. Seorang guru seharusnya dapat memilih metode yang tepat untuk digunakan dalam kegiatan pembelajaran. Pemilihan metode tersebut sangat berkaitan dengan usaha guru dalam menampilkan pembelajaran yang sesuai dengan situasi dan kondisi, oleh karena itu pencapaian tujuan pembelajaran dapat terlaksana secara optimal.

Guru harus dapat menjalankan sistem pembelajaran yang sesuai dengan tujuan yang hendak dicapai dengan menggunakan metode pembelajaran yang menarik. Salah satu metode pembelajaran yang dapat di terapkan adalah teknik pembelajaran hypnoteaching. Pada hakikatnya metode hypnoteaching merupakan strategi pembelajaran yang sangat menarik untuk diterapkan bagi pembelajaran anak Sekolah Dasar. Hypnoteaching berasal dari dua kata yakni hypnosis berarti mensugesti dan teaching berarti belajar. Jadi, hypnoteaching adalah sugesti-sugesti yang bersifat positif yang dilakukan dalam pembelajaran untuk meningkatkan prestasi belajar dari siswa. Teknik hypoteaching dilakukan bertujuan agar guru dapat mengembalikan konsentrasi dari peserta didik ketika kegiatan pembelajaran sedang berlangsung.

Dari latar belakang di atas, penulis tertarik untuk melakukan penelitian dengan judul "Efektivitas Metode Hypnoteaching dalam Pembelajaran Tematik Kelas 5 MIM 2 Babakan " untuk mengetahui adakah nilai penggunaan metode hypnoteaching dalam pembelajaran tematik untuk siswa kelas 5 MIM 2 Babakan tersebut.

\section{METODE PENELITIAN}

Jenis penelitian menggunakan
pendekatan deskriptif kualitatif yaitu penelitian yang menghasilkan prosedur analisis yang tidak menggunakan prosedur analisis statistik atau kuantifikasi lainnya (Moeleong, 2010).

Menurut Poerwandari (2005), penelitian kualitatif menghasilkan dan mengolah data yang sifatnya deskriptif, seperti transkripsi wawancara dan observasi. Meskipun studi lapangan, penelitian ini tetap melakukan kajian pustaka (library research) yang berfungsi sebagai sumber landasan teori, khususnya ketika mengkaji masalah-masalah 
yang memerlukan wawasan pustaka secukupnya, seperti pembahasan tentang metode hypnoteaching.

Teknik pengumpulan data yang digunakan dalam penelitian ini adalah dengan menggunakan triangulasi data (data gabungan) yaitu menggunakan teknik observasi, wawancara, dan dokumentasi.

Teknik analisis data yang digunakan dalam penelitian tersebut adalah teknik analisis data di lapangan model Miles and Huberman, diantaranya yaitu reduksi data, penyajian data, dan penarikan kesimpulan.

\section{HASIL DAN PEMBAHASAN}

Berdasarkan hasil observasi, wawancara mendalam, dan dokumentasi diperoleh data sebagai berikut:

\section{A. Perencanaan Pembelajaran Tematik Metode Hypnoteaching di MIM 2 Babakan}

Berdasarkan hasil wawancara dengan beberapa guru kelas V MIM 2 Babakan menjelaskan bahwa dalam melaksanakan pembelajaran mata pelajaran tematik melakukan beberapa tahap diantaranya tahap persiapan/perencanaan, tahap pelaksanaan dan tahap penutup.

Merencanakan pada dasarnya menentukkan kegiatan yang akan dilakukan pada proses pembelajaran. Perencanaan merupakan tindakan terlebih dahulu apa yang akan dilaksanakan, bagaimana mengerjakannya, apa yang harus dikerjakan dan siapa yang mengerjakannya. Madrasah Ibtidaiyah Muhammadiyah 2 Babakan merupakan sekolah yang menerapkan kurikulum 13. Pada kurikulum 13, satuan pendidikan berhak untuk menyusun kurikulum yang akan diselenggarakan. Persiapan perencanaan pembelajaran tematik yang dilakukan oleh guru di MIM 2 Babakan adalah sebagai berikut:

\section{Persiapan menentukan Tujuan Pembelajaran}

Tujuan pembelajaran merupakan tercapainya kompetensi pada siswa setelah mengikuti kegiatan pembelajaran. Tujuan pembelajaran yang hendak dicapai seharusnya ditentukkan terlebih dahulu.
Hal ini dikarenakan tujuan pembelajaran merupakan harapan yang ingin dicapai dari suatu kegiatan yang diprogramkan. Seperti yang disampaikan oleh Bapak Awal tentang tujuan pembelajaran yaitu : "Sebelum menentukkan tujuan pembelajaran maka terlebih dahulu melihat SK dan KD nya yang selanjutnya disusun dalam rencana pelaksanaan pembelajaran karena di RPP ada point tentang tujuan pembelajaran. Dan hal tersebut penting untuk menjadi tolak ukur sejauh mana proses pembelajaran yang akan dilakukan". Oleh karena itu tujuan pembelajaran merupakan poin yang sangat penting dalam pembelajaran seperti yang dikemukakan

oleh Bapak Juluno:

"Tujuan pembelajaran dapat mempengaruhi komponen pengajaran lainnya seperti: bahan pelajaran, kegiatan belajar mengajar, pemilihan metode, media, sumber dan evaluasi. Semua komponen itu harus bersesuaian dan dapat didayagunakan untuk mencapai tujuan seefektif dan seefesien mungkin untuk mencapai tujuan yang telah ditetapkan".

\section{Persiapan Menentukan Materi Ajar}

Materi ajar merupakan segala bentuk materi yang digunakan untuk membantu guru/instruktor dalam melaksanakan kegiatan pembelajaran. Materi tersebut dapat berupa materi tertulis, maupun materi tidak tertulis. Materi ajar bertujuan untuk membantu siswa dalam mempelajari sesuatu, menyediakan berbagai jenis pilihan materi ajar,

memudahkan guru dalam melaksanakan pembelajaran, serta agar kegiatan pembelajaran menjadi lebih menarik. Hal tersebut diungkapkan oleh Bapak Juluno yang menjelaskan: "Sebenarnya materi ajar sudah termuat dalam RPP, tapi terkadang hanya rangkuman. Yang jelas guru dalam mengajar harus memiliki pegangan materi. Dalam menentukkan materi harus mempertimbangkan beberapa hal, yaitu: potensi siswa, tingkat perkembangaan fisik, intelektual, manfaat untuk siswa, ada tidaknya relevansi terhadap kebutuhan siswa alokasi waktu yang disediakan”. 


\section{Persiapan dalam Memilih Metode Pembelajaran}

Metode pembelajaran merupakan cara yang digunakan untuk mengimplementasikan rencana yang sudah disusun dalam bentuk kegiatan nyata dan praktis untuk mencapai tujuan pembelajaran. Mengajar secara efektif sangat bergantung pada pemilihan dan penggunaan metode pembelajaran. Dengan menggunakan metode pembelajaran, proses belajar mengajar nampak menyenangkan dan tidak membuat para siswa tersebut suntuk, dan juga para siswa tersebut dapat menangkap ilmu dari tenaga pendidik tersebut dengan mudah. Seperti yang disampaikan oleh Bapak Juluno dalam wawancaranya:

"Saya dalam mengajar tidak hanya menggunakan satu atau dua metode agar siswa tidak jenuh, dan saya memilih metode dengan cara melihat karakteristik siswa agar tujuan pembelajaran tercapai, kita harus menggunakan metode mengajar yang baik agar siswa tidak merasa bosan ketika mengikuti pelajaran".

Metode Pembelajaran sangatlah penting dalam berlangsungnya proses pembelajaran. Beberapa metode yang digunakan oleh guru Tematik di MIM 2 Babakan diantaranya yaitu metode ceramah/ metode konvensional dalam hypnoteaching, metode demonstrasi dalam hypnoteaching, metode diskusi dalam hypnoteaching, metode tanya jawab dalam hypnoteaching, metode bermain peran dalam hypnoteaching, dan metode pemberian tugas dalam hypnoteaching.

1. Evaluasi Pembelajaran/Penilaian

Bentuk evaluasi dalam pembelajaran tematik di kelas V secara garis besar sama. Evaluasi yang dilakukan guru sangat beragam yakni melalui penugasan terstruktur mandiri tidak terstruktur. Hal tersebut sesuai dengan hasil wawancara Bapak Juluno yang menerangkan:

"Untuk evaluasi pembelajaran, guru memberikan tugas saat pembelajaran di kelas baik tugas individu ataupun kelompok dan biasanya memberikan PR agar siswa mau belajar di rumah dan kemudian kita nilai".

Hal tersebut juga dapat dilihat dari studi dokumentasi berupa bentuk evalusi yang termuat dalam buku tugas dan Penilaian Tengah Semester, Penilaian Akhir Semester, Penilaian Akhir Tahun. Selain bentuk penugasan terstruktur dan tidak terstruktur, guru di kelas yang lain juga memberikan penugasan secara tertulis maupun secara tidak tertulis.

\section{B. Pelaksanaan Pembelajaran Tematik dengan Menggunakan Metode Hypnoteaching di MIM 2 Babakan Dalam melaksanakan kegiatan}

Pembelajaran tematik guru mengacu pada Rencana Pelaksanaan Pembelajaran (RPP) kelas V. Pembelajaran Tematik dalam pelaksanaannya diampu oleh guru berbeda yakni oleh guru tematik masing-masing. Melalui observasi, wawancara, dan pengumpulan data dilakukan dikelas yang diampu oleh kedua guru tersebut .

Pada beberapa pertemuan yang peneliti amati bahwa proses belajar di kelas $\mathrm{V}$ guru memulainya dengan menyampaikan materi pembelajaran. Pada awal pembelajaran guru masuk dengan salam, dan mengajak siswa berdo'a, menanyakan kabar siswa, mengecek kehadiran siswa dan memandu siswa untuk duduk tegap dan rapi, menyampaikan tujuan pembelajaran, serta memberikan motivasi siswa dengan tepuk dinamika. Penggunaan kalimat positif untuk tepuk dinamika dan bernyanyi dengan menggunaan bahasa yang baik menunjukkan guru melakukan modelling dengan baik. Pada awal pembelajaran, guru melakukan langkah-langkah hypnoteaching yaitu kalimat-kalimat motivasi melalui tepuk dinamika dan bernyanyi.

Kegiatan pertama diawali dengan menanyakan tentang materi yang akan diajarkan, guru memuji jawaban siswa. Guru sudah melakukan salah satu langkah hypnoteaching pada kegiatan inti. Langkah hypnoteaching dilanjutkan saat kegiatan 
mengamati, sebelum membaca materi, siswa dimotivasi tentang manfaat membaca. Pada kegiatan menanya guru memuji dan melakukan pacing ketika guru mengacungkan jempol kepada siswa setelah siswa menjawab dengan benar. Pada kegiatan mencoba siswa berdiskusi guru melakukan pacing, guru berkeliling dan memberikan motivasi ketika siswa berdiskusi. Langkahlangkah hypnoteaching sudah terlihat sehingga pembelajaran diikuti oleh siswa dengan tenang dan menyenangkan.

Langkah hypnoteaching yang paling di sukai oleh siswa adalah ketika guru melakukan pacing, di dalamnya terdapat sugesti-sugesti positif sehingga menimbulkan siswa termotivasi. Langkah hypnoteaching yang dilakukan guru ini dapat menimbulkan minat belajar siswa yang baik sehingga siswa tertarik pembelajaran. Yang peneliti amati siswa mengikuti pembelajaran dengan semangat tanpa mengeluh walaupun materi banyak. Siswa menjadi menguasai pembelajaran dengan menggunakan gerakan anggota tubuh atau teknik hypnoteaching.

Metode yang dilakukan oleh guru dalam menggunakan hypnoteaching dapat membuat perhatian siswa lebih terpusat pada materi yang diberikan. Tidak hanya itu, siswa lebih mudah menghafal materi karena keadaan psikologis siswa yang nyaman dengan keadaan belajar membuat daya serap materi lebih cepat dan bertahan lama.

\section{SARAN}

Berdasarkan kesimpulan dan implikasi di atas, maka peneliti mengajukan saran sebagai berikut:

\section{Kepada Kepala Madrasah}

Selalu merespon terhadap perkembangan teori mengenai metode belajar dan menghimbau guru-guru untuk menerapkan metode belajar yang dapat menjadikan siswa lebih aktif.

2. Kepada Guru

a. Dalam pembelajaran di kelas, guru lebih kreatif menggunakan metode pembelajaran hypnoteaching .

b. Dalam pembelajaran guru memberikan kesempatan untuk melatih peserta didik dalam belajar menemukan jawabannya sendiri, guru menggunakan metode dan media belajar yang menjadikan peserta didik lebih aktif.

\section{Kepada Peserta Didik}

Hendaknya peserta didik menjadi lebih giat belajar dan berfikir bahwa pembelajaran itu menyenangkan apalagi jika guru yang mengajar menggunakan metode pembelajaran yang menarik.

\section{UCAPAN TERIMA KASIH}

Penulis mengucapkan terimakasih kepada rekan-reakan dosen di lingkungan Program Studi Pendidikan Guru Madrasah Ibtidaiyah Pascasarjana, IAIN Purwokerto atas dukungannya dalam menyelesaikan penelitian ini. Penulis juga berterimakasih kepada pihakpihak yang telah mendukung penelitian ini.

\section{DAFTAR PUSTAKA}

Adibah, Skripsi-Efektifitas Implementasi Moving Class dalam pembelajaran Pendidikan Agama Islam kelas XI SMA Negeri 1 Pleret tahun ajaran 2010/2011, Yogyakarta: Pendidikan Agama Islam Fakultas Tarbiyah dan Keguruan UIN Suka, 2011.

Arikunto, Suharsimi, Prosedur Penelitian. Jakarta: Rineka Cipta, 2005.

Moleong, Lexy J, Metodologi Penelitian Kualitatif. Bandung: PT. Remaja Rosdakarya. 2010.

Mudlofir, A. 2012. Aplikasi Pengembangan KTSP Dan Bahan Ajar Dalam Pendidikan Agama Islam. Jakarta: PT RajaGrafindo Persada.

Permendikbud No. 24 Tahun 2016 tentang Kompetensi Inti dan Kompetensi Dasar Pelajaran Pada Kurikulum 2013 Pada Pendidikan Dasar dan Pendidikan Menengah

Suci Andriani, 2014 Peranan Organisasi Pecinta Alam Dalam Meningkatkan Kesadaran Lingkungan Hidup Di Kampus Universitas Pendidikan Indonesia | repository.upi.edu perpustakaan.upi.edu

Sudjana, Nana \& Ibrahim. 2012. Penelitian dan Penilaian Pendidikan (Cetakan 
ke7). Bandung: Sinar Baru Algensindo

Sudrajat, A. 2008. Pengembangan Bahan Ajar Materi Pembelajaran PAI. Makalah disajikan dalam Workshop Bimbingan Teknis Penguatan KTSP SMP bagi Tim Pengembang Kurikulum/Verfikator Propinsi, di Hotel Graha Dinar, Cisarua Bogor pada Maret 2008

Sugiyono, Metode Penelitian Pendidikan, Pendekatan Kuantitatif, Kualitatif, dan R\&D, Bandung: Alfabeta, 2011.

Tim Dirjen GTK. 2019. Buku Pegangan Pembelajaran Berorientasi Pada Keterampilan Berpikir Tingkat Tinggi. Jakarta: Kementerian Pendidikan dan Kebudayaan 